\title{
Plant oil mixtures as a novel botanical pesticide to control gregarious locusts
}

\author{
Zainab Ali Saad Abdelatti ${ }^{1,2} \cdot$ Manfred Hartbauer $^{1}$
}

Received: 16 May 2019 / Revised: 17 October 2019 / Accepted: 19 October 2019 / Published online: 1 November 2019

(c) The Author(s) 2019

\begin{abstract}
For thousands of years, large locust swarms have caused severe problems in agriculture. People fight against current outbreaks by using chemical pesticides or an insect fungus known as Green Muscle ${ }^{\mathrm{TM}}$. While chemical pesticides may be harmful for humans and non-target species, the sporulation of the fungus takes a long period of time and requires conditions of high humidity that are not always found in the field. In this study, we tested the toxicity of a linseed oil/bicarbonate emulsion against gregarious desert locusts and screened for plant essential oils that enhance its toxicity. Finally, we combined three essential oils to develop a novel formulation that is effective against the desert and migratory locust species after single spray treatment. Within $24 \mathrm{~h}$, this formulation caused a mean mortality rate of $80 \%$ and $100 \%$ of desert and migratory locusts, respectively. Its toxicity is based on a synergistic effect resulting from the combination of caraway, orange peel and wintergreen oils. In addition, we tested this botanical pesticide on two beetle species regarded either as alternative or beneficial non-target species. The first species, mealworm beetles, did not suffer from the spray treatment and behaved normally after 8 days. In contrast, $67.7 \%$ of ladybird adults died in the same time span. Interestingly, the growth of wheat seedlings was almost unaffected by spraying this botanical pesticide. These results suggest this botanical pesticide can be used as a strong agent against desert and migratory locusts, but needs to be used with care to minimize unwanted side effects on the ecosystem.
\end{abstract}

Keywords Locust swarm $\cdot$ Linseed oil $\cdot$ Essential oils $\cdot$ Mealworm beetles $\cdot$ Ladybird beetles $\cdot$ Pest management $\cdot$ Botanical pesticide

\section{Key message}

- In many countries, locust outbreaks still constitute a big problem for farmers. Current pest management is potentially harmful for humans.

- We developed a novel botanical pesticide against locusts that consisted of natural plant oils.

Communicated by M.B. Isman.

Electronic supplementary material The online version of this article (https://doi.org/10.1007/s10340-019-01169-7) contains supplementary material, which is available to authorized users.

Manfred Hartbauer

manfred.hartbauer@uni-graz.at

1 Institute of Biology, University of Graz, Universitätsplatz 2, 8010 Graz, Austria

2 Department of Zoology, Faculty of Science, South Valley University, 83523 Qena, Egypt
- We identified orange peel, caraway and wintergreen oils to be effective against locusts when added to a linseed oil/bicarbonate emulsion.

- Our novel botanical pesticide had a synergistic toxic effect.

- This formulation is highly effective against two gregarious locust species and is considered harmless for humans.

\section{Introduction}

Locusts constitute a major problem for agricultural crops (Wright 1986; Brader et al. 2006; Millist and Abdalla 2011; Latchininsky 2013; Zhang and Hunter 2017). They can transform reversibly between two extreme phases, solitary and gregarious. The locusts differ in both of these phases in terms of their morphology, physiology and behavior (Steedman 1988; Uvarov 1966). The distribution of gregarious locusts extends from Africa through the Middle East to Asia, 
South and Central America, Australia and Southern Europe. When these species transform into the gregarious phase, they form locust swarms that can devour entire fields and cause extensive crop damage over a very short period of time. A small swarm of locusts contains thousands of individuals that spread over several hundred square meters, but large swarms contain up to 80 million individuals per $\mathrm{km}^{2}$ and can infest more than $1000 \mathrm{~km}^{2}$. Since a swarm can cover a distance of $100 \mathrm{~km}$ per day (Steedman 1988), farmers regard gregarious locusts as one of the most destructive plagues on earth.

Before 1980, persistent organochlorine compounds like dieldrin were used extensively to combat locust swarms (Steedman 1988). Because organochlorine compounds have been banned, locust control is currently mainly based on organophosphorus pesticides. The reduced persistence of these compounds makes them less effective than dieldrin (Arthurs 2008). From 2003-2005, authorities applied thirteen million liters of chemical pesticides to thirteen million hectares of land to control desert locust outbreaks (Lecoq 2010). This intensive use of chemical pesticides is probably underestimated and has led to severe environmental problems, which have had harmful side effects on the overall ecosystem (WHO 1990, 2012; Alavanja 2009; Alavanja and Bonner 2012; Köhler and Triebskorn 2013; Carvalho 2017). Therefore, there is an interest in developing potentially safe alternatives or additional control technologies (Nicolopoulou-Stamati et al. 2016). Natural enemies cannot be used because of the rapid development and migration of locusts (Steedman 1988). Over the past 20 years, the Food and Agriculture Organization of the United Nations (FAO) has been working with several countries to develop a biopesticide that is based on the fungus Metarhizium acridum, which infests locusts and grasshoppers (Lecoq 2010). The commercial name of this bio-pesticide is Green Muscle ${ }^{\mathrm{TM}}$. In 2009, the desert Locust Control Committee located in Rome recommended that properly trained professional teams use Green Muscle ${ }^{\mathrm{TM}}$ operationally for the preventive control of the desert locust when the temperature is suitable (FAO 2009). Because Green Muscle ${ }^{\mathrm{TM}}$ has several shortcomings, such its long incubation period, scientists urgently need to carry out more studies to develop effective agents that control locusts and do not have severe side effects on the ecosystem.

In recent years, plant oils have received more and more attention as alternative, potentially valuable compounds that can be used against specific pests and some important plant pathogens (Isman 2004). Several studies have confirmed that plant oils could be used as natural pesticides to control agricultural pests (e.g., Aly et al. 2012; Tak 2015; Tripathi et al. 2009) and plant diseases (e.g., Arshad et al. 2014; Sturchio et al. 2014; EL Rasheed and EL Rasheed 2017; Elshafie and Camele 2017). Most natural plant oils are suitable for organic agriculture because they are non-residual, non-toxic to humans and vertebrate animals, easy to prepare and apply, cheap, effective and natural (Elshafie and Camele 2017). Plant oils are available as vegetable oils and essential oils. The first type is produced by expressing the oils from the seeds and parts of the plant (e.g., sunflower oil, olive oil, linseed oil). The second type is extracted from the plants by means of distillation (e.g., orange oil, peppermint oil, garlic oil, lavender oil). Essential oils are volatile compounds and must be diluted in carrier oils before their use. For centuries, plant oils or extracts have been used in alternative medicine, aromatherapy, as food flavorings, perfumes, preservatives and biological agents (Tak 2015). Recent studies have suggested that essential oils are effective against locusts and grasshoppers. For example, Sharaby et al. (2012) suggested that the essential oils of garlic, eucalyptus and mint could be used in the integrated pest management (IPM) against the grasshopper Heteracris littoralis. Abdellah et al. (2013) tested the effect of the crude leaf essential oil obtained from Peganum harmala $\mathrm{L}$. (wild rue) on larvae and adult individuals of the desert locust. They reported that the desert locusts displayed toxic effects, imbalance problems and convulsive movements. Halawa and Hustert (2014) found that lovage essential oil and its main components, limonene, impaired the ventilation of locusts at low concentrations. Lahsen et al. (2015) found that rosemary essential oil displayed a remarkably toxic effect against the moroccan locust (Dociostaurus maroccanus). In all of these studies, essential oils were found to affect locusts in different ways, but oils have not been tested on non-target species, such as beetles that are known to play important roles in the ecosystem.

In this study, we developed a novel mixture of plant oils that has highly toxic effects on two target species of gregarious locusts: the desert locust Schistocerca gregaria and the migratory locust Locusta migratoria. The intension was to coat the locusts with a thin layer of an oil that is difficult for the insect to remove. We used linseed oil, a drying oil that becomes viscous over time. In order to speed up the drying process, we mixed it with a saturated solution of sodium bicarbonate, which may have an additional benefit in that it is used for the control of fungal plant diseases (Horst et al. 1992; Kuepper et al. 2001). In order to increase the toxic effect of the linseed emulsion, we added three essential oils that were found to be toxic for desert locusts in a screening study. The toxic effect of the combination of effective essential oils sprayed at a low concentration on two locust species was studied $24 \mathrm{~h}$ after single spray treatment. To test the toxic effect of this botanical pesticide on a beneficial non-target species and an alternative non-target species, we also sprayed adult ladybirds and their larvae, as well as adult mealworm beetles. We selected ladybird beetles as a nontarget species because of its important role in the ecosystem (e.g., control of plant lice) and also treated mealworm beetles to determine whether the pesticide has a possibly harmful effect on another small beetle species. To study the effect of this formulation on the growth of grass, we sprayed it on wheat seedlings and exposed them to sunlight. 


\section{Materials and methods}

\section{Insects}

Desert locusts (Schistocerca gregaria) and migratory locusts (Locusta migratoria) were purchased in the gregarious phase from a breeding stock of the Buchner company in Austria. Locusts were maintained in a crowded colony at the Institute of Zoology in Graz. About 100 locusts were kept in a glass terrarium with dimensions of $60 \times 30 \times 30 \mathrm{~cm}$. Individuals used in this study were taken from crowded colonies about 2 weeks after their last molt. The light/dark cycle was $12: 12 \mathrm{~h}$, and the average temperature in the terrarium was $26 \pm 2{ }^{\circ} \mathrm{C}\left(\right.$ mean \pm SD) at night and $33 \pm 2{ }^{\circ} \mathrm{C}($ mean \pm SD $)$ during the day. The relative humidity was $45-60 \%$. The locusts' diet consisted of organic wheat seedlings and organic wheat bran (dm-Drogerie markt, Karlsruhe, Germany), both in the breeding stock and in the crowded colony.

Adults and larvae of the mealybug ladybird (Cryptolaemus montrouzieri) were purchased from a breeding stock of the Biohelp company (Vienna, Austria). Ladybird adults were kept in plastic boxes with dimensions of $20 \times 12 \times 14 \mathrm{~cm}$, each containing 30 individuals. About 100 ladybird larvae (final larval instar) were kept in a plastic box with dimensions of $20 \times 12 \times 14 \mathrm{~cm}$, covered with transparent fabric, which contained a small piece of paper towel $(12 \times 12 \mathrm{~cm})$. The light/dark cycle was $12: 12 \mathrm{~h}$, the temperature was $22 \pm 2{ }^{\circ} \mathrm{C}$ (mean $\pm \mathrm{SD}$ ), and the relative humidity was $40 \pm 16 \%$ (mean $\pm \mathrm{SD}$ ). The diet for ladybird adults and larvae consisted of sweetened water gel ( $2 \mathrm{ml}$ of $50 \%(\mathrm{~g} / \mathrm{V})$ glucose solution added to $10 \mathrm{~g}$ water gel (Trixie Heimtierbedarf, Tarp, Germany)).

Adult mealworm beetles (Tenebrio molitor) were taken from the laboratory breeding stock maintained at the Institute of Biology in Graz. Beetles were exposed to a light/dark cycle of 12:12 $\mathrm{h}$ and maintained at an ambient temperature of $22{ }^{\circ} \mathrm{C}$ and $50 \%$ relative humidity. Their diet consisted of dry bread, apples, fish food and oatmeal (SPAR Österreich Warenhandels AG, Salzburg, Austria).

\section{Feeding plants}

Seeds of organic wheat (dm-Drogerie markt, Karlsruhe, Germany) were planted in plastic pots that had been filled halfway with perlite (Plant!t, HydroGarden Wholesale Supplies Ltd, Binley, Coventry, CV3 2NT, UK) and covered with soil (Organic soil from EuFlor Inc., Munich, Germany). Pots were watered daily, and plants were exposed to a light/ dark schedule of 12: $12 \mathrm{~h}$. After 1 week, the wheat seedlings were placed in the terrarium to feed the locusts.

\section{Oil emulsions and suppliers}

In this study, we used linseed oil as insecticidal agent to impair the motion of locusts by means of an oil that becomes viscous over time. In order to accelerate the drying process of this oil, the linseed oil was mixed with a saturated solution of sodium bicarbonate.

The linseed/bicarbonate emulsion consisted of:

Cold-pressed organic linseed oil (Linum usitatissimum), (Natur-Pur brand, Spar Österreich) and

saturated sodium bicarbonate solution (IUPAC name: sodium hydrogen carbonate $\mathrm{NaHCO}_{3}$, commercial name: baking soda), purchased from Dr. Oetker, Villach, Austria.

We assessed the hardening process of the linseed/bicarbonate emulsion $(56: 44 \%(\mathrm{v} / \mathrm{v}))$ in a petri dish for 1 day (see Fig. 1). Linseed oil was stored in a dark bottle at $4{ }^{\circ} \mathrm{C}$.

To increase the harmful effect caused by the hardening of the linseed oil emulsion, the following organic essential oils were added individually and tested for their insecticidal effects:

Peppermint oil (Mentha piperita), orange peel oil (Citrus aurantium dulcis), ginger oil (Zingiber officinale) and eucalyptus oil (Eucalyptus globulus). These oils were purchased from Primavera (Oy-Mittelberg, Germany).

Basil oil (Ocimum basilicum) and wintergreen oil (Gaultheria procumbens), both purchased from Naissance (Neath, UK).

Garlic oil (Alium sativum) purchased from Dragonspice Naturwaren (Reutlingen, Germany).

Caraway oil (Carum carvi) purchased from BombastusWerke (Freital, Germany).

Clove oil (Eugenia carophyllus) purchased from GreenMade (V03 Trading GmbH, Willich, Germany).

Birch oil (Betula lenta) purchased from Laboratoire Centiflor (Entrechaux, France).

All essential oils were $100 \%$ pure and were stored at room temperature in a dark location. The selection of these essential oils was based on the findings of previous scientific studies in which some of these essential oils (or oils with similar effective components) were investigated for their effects against various insects such as termites, locusts, moths and beetles (Aly et al. 2012; Halawa and Hustert 2014; Tak et al. 2016, 2017; Tripathi et al. 2009).

\section{Preparation of the linseed/bicarbonate emulsion}

The saturated sodium bicarbonate solution was prepared by dissolving $1 \mathrm{~g} \mathrm{NaHCO}_{3}$ powder in $10 \mathrm{ml}$ distilled water 
Fig. 1 Hardening of the linseedbicarbonate emulsion. a Image of the emulsion after mixing linseed oil and bicarbonate solution. b Image of the viscous film formed after $24 \mathrm{~h}$
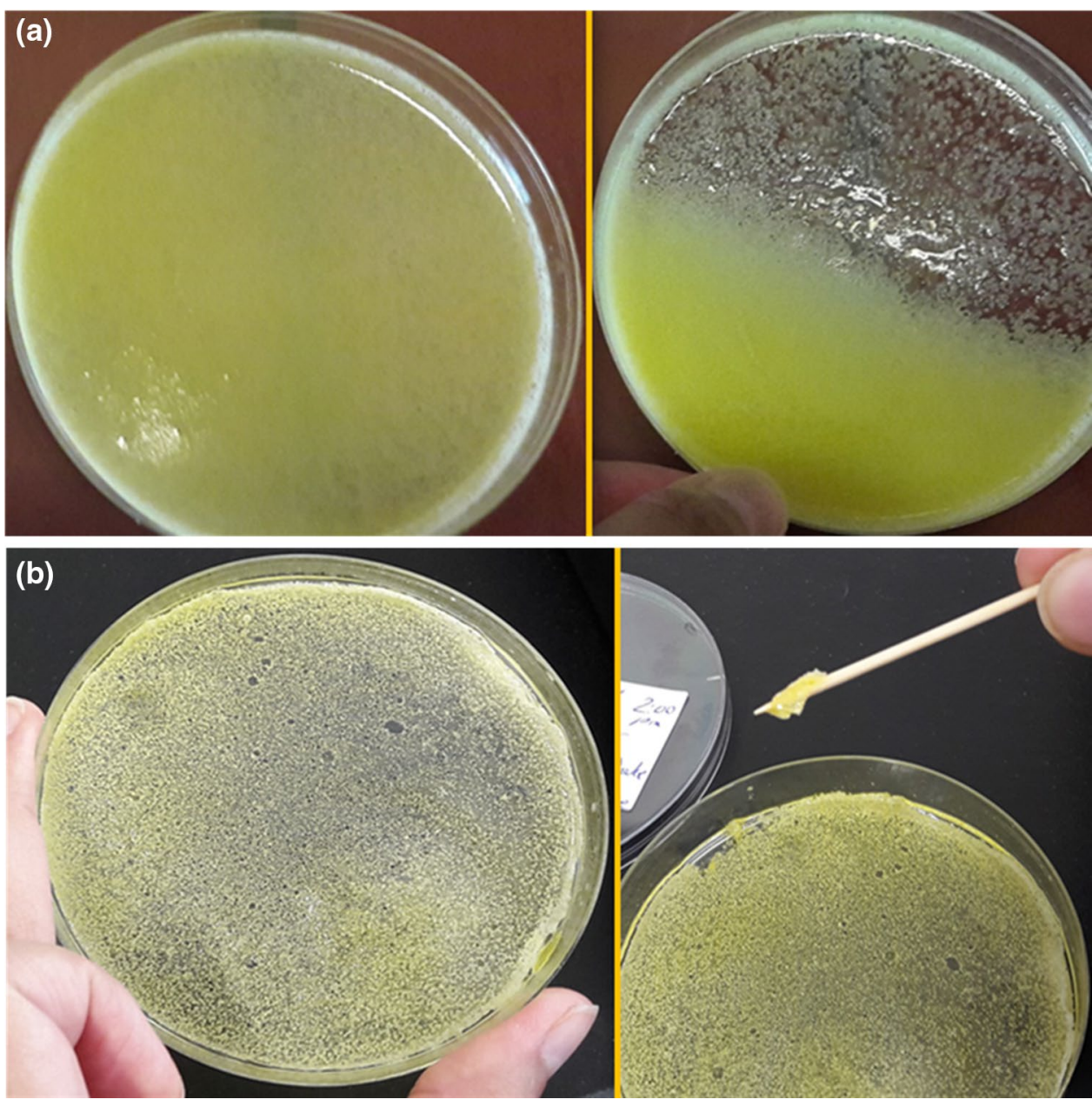

(10\%). The supernatant was then added to the linseed oil using a $50 \mathrm{ml}$ plastic centrifuge tube. Essential oils were added to this emulsion using an automatic calibrated pipette (Eppendorf Inc.). All oil emulsions were mixed with a vortex device (VF2, Ika labortechnik, Janke \& Kunkel, Germany) before spray treatment.

\section{Screening for effective essential oils}

To screen for essential oils that are effective against desert locusts ( $S$. gregaria), we sprayed $4.9 \mathrm{ml}$ of different oil mixtures (equal to five pump sprays) into each box containing ten individuals. Since the preliminary experiment had demonstrated a higher robustness of desert locusts against linseed/bicarbonate treatment as compared with migratory locusts, we selected the former for this screening study. The number of living and dead individuals was counted after $24 \mathrm{~h}$ by gently shaking the insect boxes. Individuals that were unable to move and breathe normally (absent telescopic abdominal movement) were regarded as dead in this study, because 'frozen' individuals did not recover from this state during the observation period of
$40 \mathrm{~h}$. The effects caused by essential oils were compared with three control situations.

Controls and treatments used in the screening experiment:

Control 1: no treatment

Control 2: spraying pure linseed oil

Control 3: spraying saturated sodium bicarbonate solution $(10 \%)$

Treatments:

Linseed/bicarbonate emulsion: $10 \mathrm{ml}$ linseed oil $(55.6 \%)+8 \mathrm{ml}$ aqueous $10 \%$ sodium bicarbonate solution $(44.4 \%)$

$1 \mathrm{ml}$ pure essential oil (garlic, caraway, clove, peppermint, orange, ginger, birch, eucalyptus, or basil), each was added to $18 \mathrm{ml}$ linseed/bicarbonate emulsion (resulting proportions: $5.3 \%$ essential oil, $52.6 \%$ linseed oil and $42.1 \%$ sodium bicarbonate solution).

Adult desert locusts (mature: about 2 weeks after last molt) were placed in plastic boxes with dimensions of $20 \times 12 \times 14 \mathrm{~cm}$. Individuals used in experiments appeared 
healthy and were able to jump. The boxes were covered with transparent fabric. Each box contained ten locusts (half females and half males), a small piece of paper towel (one layer of paper tissue of $12 \times 12 \mathrm{~cm}$ ) and some wheat grass (about 35 stalks). After shaking the oil emulsion, $4.9 \mathrm{ml}$ was sprayed on the insects and their food using a pump sprayer (hand spray device; Kläger Plastik, Neusäss, Germany; nozzle diameter $=0.6 \mathrm{~mm}$ ). The food was also sprayed to screen for the oral toxicity and contact-dependent toxic effects caused by essential oils. The insect boxes were turned by $90^{\circ}$ to spray the locusts from top (distance between the sprayer and locusts $\approx 20 \mathrm{~cm}$ ) and keep the aerosol inside the box. The same amount of oil emulsion that was applied to insects was also sprayed on a weighing dish to quantify the applied volume. The paper towel in the boxes soaked up the remaining oil emulsion.

\section{Effect of the combination of essential oils}

Essential oils that contributed to a high mortality rate of adult desert locusts (orange peel, birch oil and caraway oil) were combined in different concentrations to test different botanical pesticide formulations as agents against locusts. Garlic oil has a strong smell and was not used in these formulations. We also replaced birch oil by wintergreen oil, since it is more readily available and has the same active ingredient (methyl salicylate). Finally, two slightly different formulations caused a high mortality in desert and migratory locusts (data not shown). The botanical pesticide formulation used in this study (see description below) was found to be the most effective. In order to reveal a possible synergistic effect caused by the combination of three essential oils, we performed a 'synergism experiment.' In this experiment, essential oils were sprayed at low concentrations either individually or in combination (termed botanical pesticide treatment) on desert and migratory locusts. We specifically compared the mortality rate caused by orange peel, caraway and wintergreen oils with a botanical pesticide formulation that contains all of these oils. The treatment of locusts in the synergism experiment was similar to the treatment used during the screening experiment with the exception that fresh grass was provided after the spray treatment $(4.9 \mathrm{ml}$ was sprayed in control 2 and each treatment). This allowed us to discriminate between a toxic effect caused by physical contact with the oil emulsion and oral toxicity. The following controls and treatment were tested:

Control 1: no treatment

Control 2: Linseed/bicarbonate emulsion: $10 \mathrm{ml}$ linseed oil $(55.6 \%)+8 \mathrm{ml}$ aqueous $10 \%$ sodium bicarbonate solution $(44.4 \%)$
Caraway treatment: Linseed/bicarbonate emulsion consisting of $10 \mathrm{ml}$ linseed oil (52.6\%) and $8.5 \mathrm{ml}$ aqueous $10 \%$ sodium bicarbonate solution $(44.7 \%)+0.5 \mathrm{ml}$ caraway oil (2.6\%)

Orange peel oil treatment: Linseed/bicarbonate emulsion consisting of $10 \mathrm{ml}$ linseed oil $(52.6 \%)+8.75 \mathrm{ml}$ aqueous $10 \%$ sodium bicarbonate solution $(46.1 \%)+0.25 \mathrm{ml}$ orange peel oil (1.3\%)

Wintergreen treatment: Linseed/bicarbonate emulsion consisting of $10 \mathrm{ml}$ linseed oil $(52.6 \%)+8.75 \mathrm{ml}$ aqueous $10 \%$ sodium bicarbonate solution $(46.1 \%)+0.25 \mathrm{ml}$ wintergreen oil (1.3\%)

Botanical pesticide treatment: $18 \mathrm{ml}$ linseed/bicarbonate emulsion $(10 \mathrm{ml}$ linseed oil (52.6\%) and $8 \mathrm{ml}$ aqueous $10 \%$ sodium bicarbonate solution $(42.1 \%))+0.25 \mathrm{ml}$ orange peel oil $(1.3 \%)+0.5 \mathrm{ml}$ caraway oil $(2.6 \%)+0.25 \mathrm{ml}$ wintergreen oil $(1.3 \%)$.

Each treatment was repeated five times, and the average mortality rates were calculated.

\section{$\mathrm{LC}_{50}$ test of the botanical pesticide}

The lethal concentration $50 \%\left(\mathrm{LC}_{50}\right)$ of our botanical pesticide formulation was assessed within $40 \mathrm{~h}$ to reveal whether it had been applied at a concentration that was effective to control desert locusts, which had been found to have a lower mortality rate as compared to migratory locusts. For this purpose, we diluted the botanical pesticide (same composition as in the synergy experiment) with distilled water to create different concentrations and sprayed it on adult desert locusts (S. gregaria). A similar treatment procedure was used as in the screening test, but fresh grass was added after the spray treatment. Individuals were counted either as dead or alive when they did not move and breathe after gently shaking the box. $\mathrm{LC}_{50}$ experiments were repeated three times, and the average mortality rate was calculated. The dilutions of the botanical pesticide for the $\mathrm{LC}_{50}$ experiment were:

$5 \mathrm{ml}$ botanical pesticide $(25 \%)+15 \mathrm{ml}$ distilled water $(75 \%)$

$10 \mathrm{ml}$ botanical pesticide $(50 \%)+10 \mathrm{ml}$ distilled water $(50 \%)$

$15 \mathrm{ml}$ botanical pesticide $(75 \%)+5 \mathrm{ml}$ distilled water $(25 \%)$

$18 \mathrm{ml}$ botanical pesticide $(90 \%)+15 \mathrm{ml}$ distilled water $(10 \%)$

$20 \mathrm{ml}$ botanical pesticide (100\%)

The $\mathrm{LC}_{50}$ was calculated after performing a linear regression on the averaged mortality rates obtained at different concentrations. 


\section{Botanical pesticide treatment of ladybirds}

Ladybirds play an important role in many ecosystems and were considered to be a beneficial non-target species in this study. To determine whether our botanical pesticide formulation (see above) could possibly harm ladybirds, we sprayed adults and larvae of the mealybug ladybird species C. montrouzieri in an additional experiment. Thirty ladybird adults and 15 ladybird larvae, all retrieved from the purchased colony, were put in separate plastic boxes with dimensions of $20 \times 12 \times 14 \mathrm{~cm}$. The boxes were covered with transparent fabric. Each box contained a small piece of paper towel $(12 \times 12 \mathrm{~cm})$ to soak up the remaining oil. Due to the very small size of ladybird species, we reduced the amount of the sprayed volume to only $2 \mathrm{ml}$ of the botanical pesticide formulation to prevent the submersion of individuals. The oil emulsion was sprayed from above in each box (equal to two pump sprays). This experiment was repeated four times with adults. In each box, a small petri dish containing $10 \mathrm{~g}$ of water gel (Trixie Heimtierbedarf, Tarp, Germany) with $2 \mathrm{ml}$ glucose solution $(50 \%(\mathrm{~g} / \mathrm{V}))$ was provided as food, initially after the spraying treatment and then on a daily basis.

\section{Botanical pesticide treatment of mealworm beetles}

To determine whether our botanical pesticide formulation (see above) had a possibly harmful effect on an alternative non-target species, adult mealworm beetles (T. molitor) were sprayed in an additional experiment. For this purpose, 16 mealworm individuals were caged in plastic boxes with dimensions of $9 \times 9 \times 6 \mathrm{~cm}$ that had pores on two sides to allow for ventilation. Individuals used in this experiment appeared to be healthy. All boxes contained a small piece of an apple, $3.5 \mathrm{~g}$ of oat flakes and $0.5 \mathrm{~g}$ of fish food (ASTRA Aquaria $\mathrm{GmbH}$, Bissendorf, Germany). The botanical pesticide emulsion was shaken before spraying it on the beetles and on the food (except apple pieces, which were added later). Because smaller boxes were used for the beetles, only $2.9 \mathrm{ml}$ of the botanical pesticide formulation was sprayed in each box (equal to three pump sprays). After spray treatment, the boxes were closed with a plastic cover (lacking pores). This experiment was repeated four times. Every second day, a small piece of an apple was provided as fresh food. The number of living and dead individuals was counted after gently shaking the boxes.

\section{Effect of the botanical pesticide on the feeding activity}

The effect of the botanical pesticide on the feeding activity of adult desert locusts (S. gregaria) was investigated in a separate experiment where the same amount of grass (36 stalks) was added to three boxes of dimensions $20 \times 12 \times 14 \mathrm{~cm}$. Each box contained 10 adult locust individuals and a small piece of paper towel (one layer of kitchen paper tissue of dimensions $12 \times 12 \mathrm{~cm}$ ). One box served as the no-treatment control. Locusts in the second box were sprayed together with the grass $(4.9 \mathrm{ml}$ of the botanical pesticide formulation). Desert locusts in the third box were sprayed with same amount of the botanical pesticide, but fresh grass stalks were added right after treatment. $24 \mathrm{~h}$ later, images were taken from each box (see Fig. S2).

\section{Ambient conditions during experiments}

All experiments were performed on a work bench with medium airflow and a light/dark cycle of 12:12 h. During the experiments, the temperature was $24.5 \pm 2{ }^{\circ} \mathrm{C}($ mean $\pm \mathrm{SD})$, and the relative humidity was $42 \pm 11 \%($ mean $\pm \mathrm{SD})$.

\section{Effect of the botanical pesticide on plant growth}

A botanical pesticide that is based on hardening linseed oil may adversely affect plant growth because of its viscosity. In order to study the potentially harmful effect on plant growth, the botanical pesticide emulsion was sprayed on wheat seedlings that were exposed to sunlight on a balcony in Graz. In this experiment, $4.9 \mathrm{ml}$ of the botanical pesticide emulsion (equal to five pump sprays) was sprayed on each grass pot and grass growth was monitored over 22 days. The wheat seedlings were purchased as "cat grass" from a pet store (Zoo Muser, Graz, Austria). The temperature during this experiment was between $17-30{ }^{\circ} \mathrm{C}$, and the relative humidity was $49.2-62.7 \%$. Each control and treatment group consisted of three pots of wheat seedlings that were submersed in water to provide the same amount of water.

\section{Mortality rate calculations}

The mortality rates were calculated in Microsoft Excel 2016 using Eq. (1):

Percentage observed mortality
$\quad=\left(\frac{\text { total number of dead individuals }}{\text { total number of treated individuals }}\right) * 100$ 
According to the World Health Organization's (WHO) test procedures for insecticide resistance monitoring (Global Malaria Programme 2016), Eq. (2) was used for the calculation of mortality rates that takes the value of the control mortality into account. If the control mortality is higher than $5 \%$ and lower than $25 \%$, then the mortality rate of treatment groups was corrected according to the Schneider-Orelli formula (Püntener 1981) shown in Eq. (2).

Percentage corrected mortality

$$
=\left(\frac{\% \text { observed mortality }-\% \text { control mortality }}{100-\% \text { control mortality }}\right) * 100
$$

The corrected mortality was calculated for ladybirds and mealworm beetles, since the mortality of locusts in the control group was less than 5\%. To cross-check the corrected mortality rates, we calculated them a second time using the Schneider-Orelli method provided on this website: http:// www.ehabsoft.com/ldpline/onlinecontrol.htm. The average mortality is given as the mean mortality rate of different replicates ( \pm standard deviation).

\section{Statistical analysis}

Mortality rates of the locusts and beetles were tested for statistically significant differences by performing the $Z$-test with the Yates correction, which takes the sample number into account. Significant differences between the control and the treatment groups are indicated by an asterisk in Figs. 2, 3 and 4. All statistical tests were performed in Sigma Plot version 13 (Systat Software Inc.). The linear regression performed for the calculation of the LC 50\% of the botanical pesticide was calculated in Excel (version 2016, Microsoft Inc.). To determine whether a possible synergistic toxic effect was caused by a mixture of four oils, we calculated the expected mortality rate according to what is called the response addition or Bliss Independence (Bliss 1939) and compared this rate with the observed mortality rate by performing a Chi square test (equation described in Tounou et al. 2008). The expected mortality rate caused by the addition of the toxicity of four oils was calculated by modifying equation two as stated in Cedergreen (2014).

\section{Results}

\section{Screening for effective essential oils}

In a petri dish, the linseed oil/bicarbonate emulsion (56:44\% (v/v), Fig. 1a) hardened within $24 \mathrm{~h}$ and became sticky and viscous (compare Fig. 1a with 1b). This emulsion caused a moderately toxic effect when sprayed on adult desert locusts (Fig. 2), whereas spraying either linseed oil or bicarbonate solution failed to harm these insects. Linseed oil/bicarbonate-treated desert locusts that survived $24 \mathrm{~h}$ had difficulties moving quickly and were unable to jump; they appeared as though frozen. The amount of oil sprayed in this screening experiment was too low to create a sticky surface inside the box upon which insects adhered. To enhance the toxic effect caused by the hardening of linseed oil (see Fig. 2), different essential oils were added to this oil emulsion and sprayed on desert locusts in the screening experiment. Figure 2 shows the mean mortality rates of the desert locust 1 day after a single spray treatment with each of nine different oil emulsions. The mortality rates of desert locusts were equal or exceeded $70 \%$ when each of the garlic, orange, caraway and

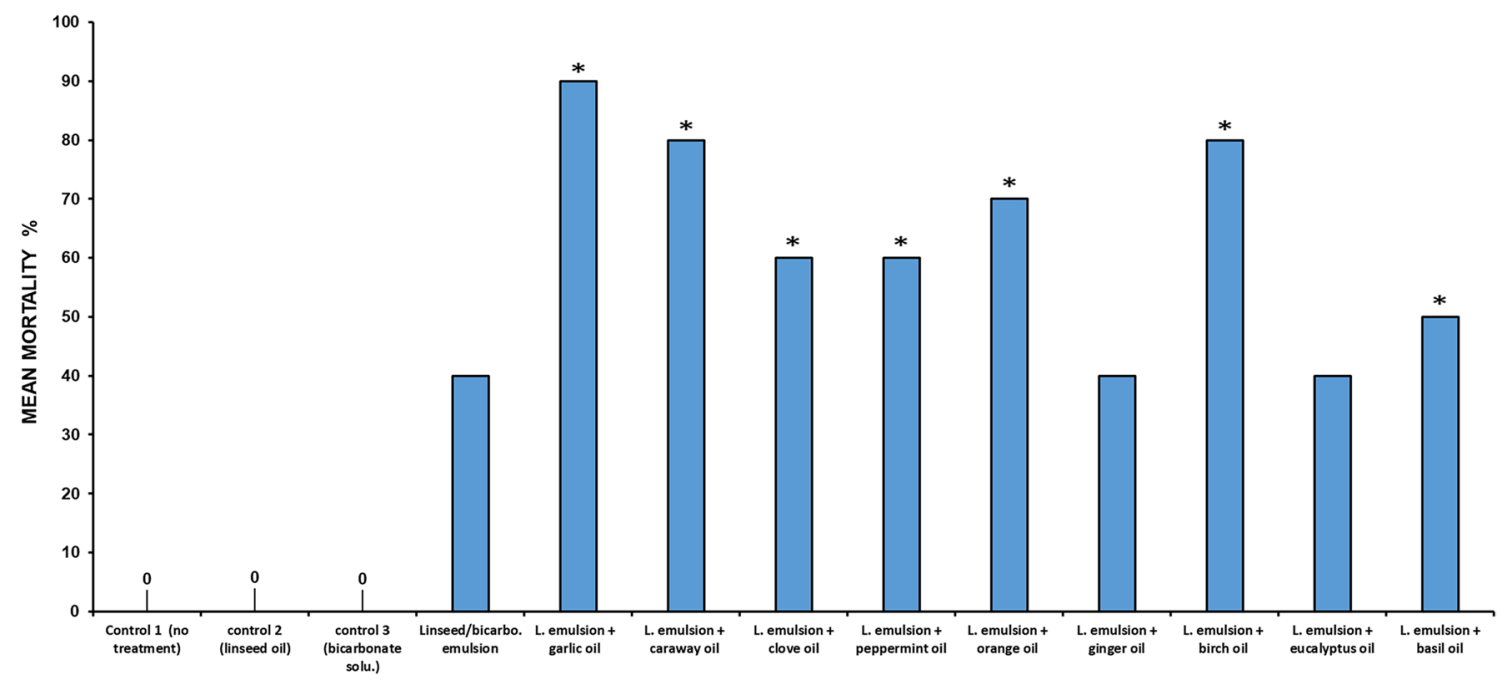

Fig. 2 The mortality rate of desert locusts in the screening experiment. The mortality rate of the desert locusts is shown after $24 \mathrm{~h}(N=10)$. *Indicates the significant difference between controls and treatment $(p<0.05, Z$-test) 


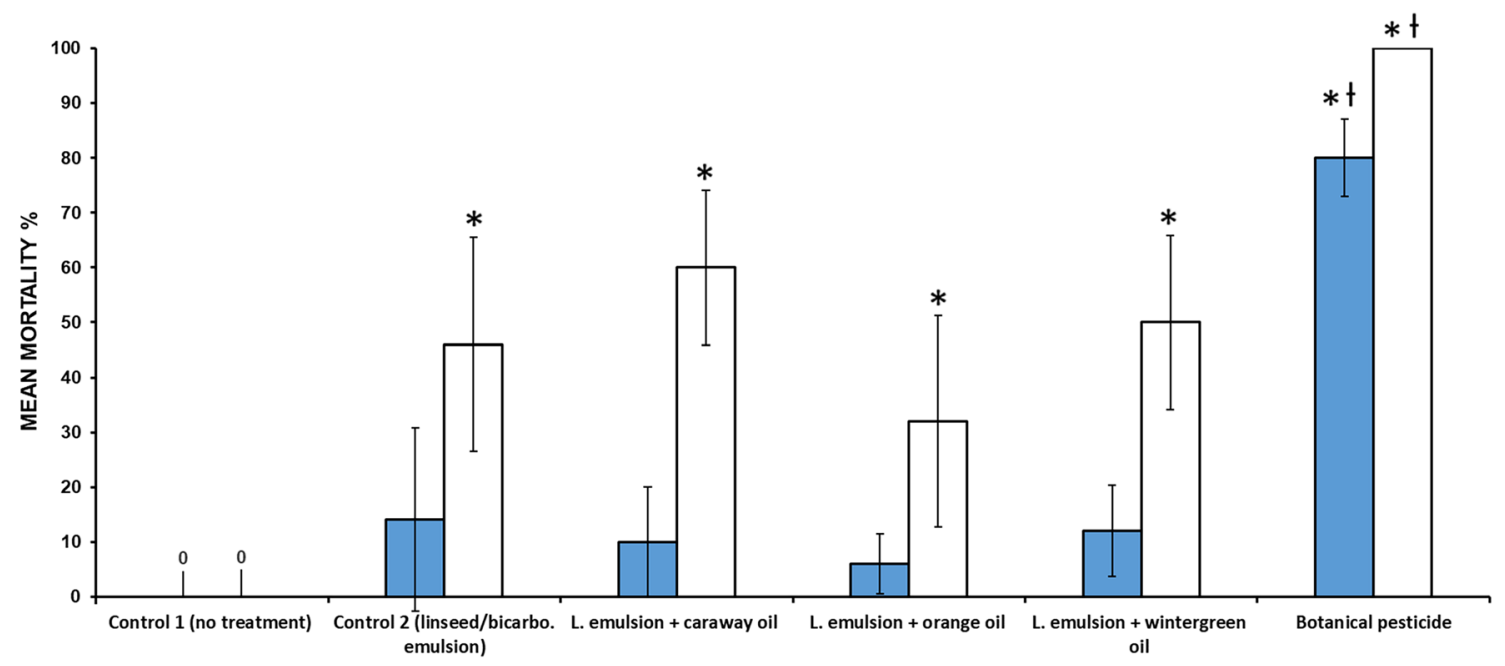

Fig. 3 Botanical pesticide experiment. Essential oils were added either individually or in combination to the linseed oil emulsion and the mean mortality rate of desert and migratory locusts was calculated after a single spray treatment. The mean mortality rate of desert locusts (blue bars, $N=10$, five replicates) and migratory locusts (blank bars, $N=10$, five replicates) is shown after $24 \mathrm{~h}$. *Indicates a significant difference between control 1 and treatment $(p<0.05$, $Z$-test). ${ }^{\mathrm{I}}$ Indicates a significant difference between control 2 and treatment $(p<0.05, Z$-test $)$

Fig. 4 Beetle experiment. The mortality rates of two beetle species after single spray treatment with the botanical pesticide formulation. The mean corrected mortality rate of mealworm beetles (green bars, $N=16$, four replicates) and the mean corrected mortality rate of ladybird adults (blank bars, $N=30$, four replicates) 8 days after treatment. *Indicates a significant difference between control and treatment $(p<0.05$, $Z$-test)

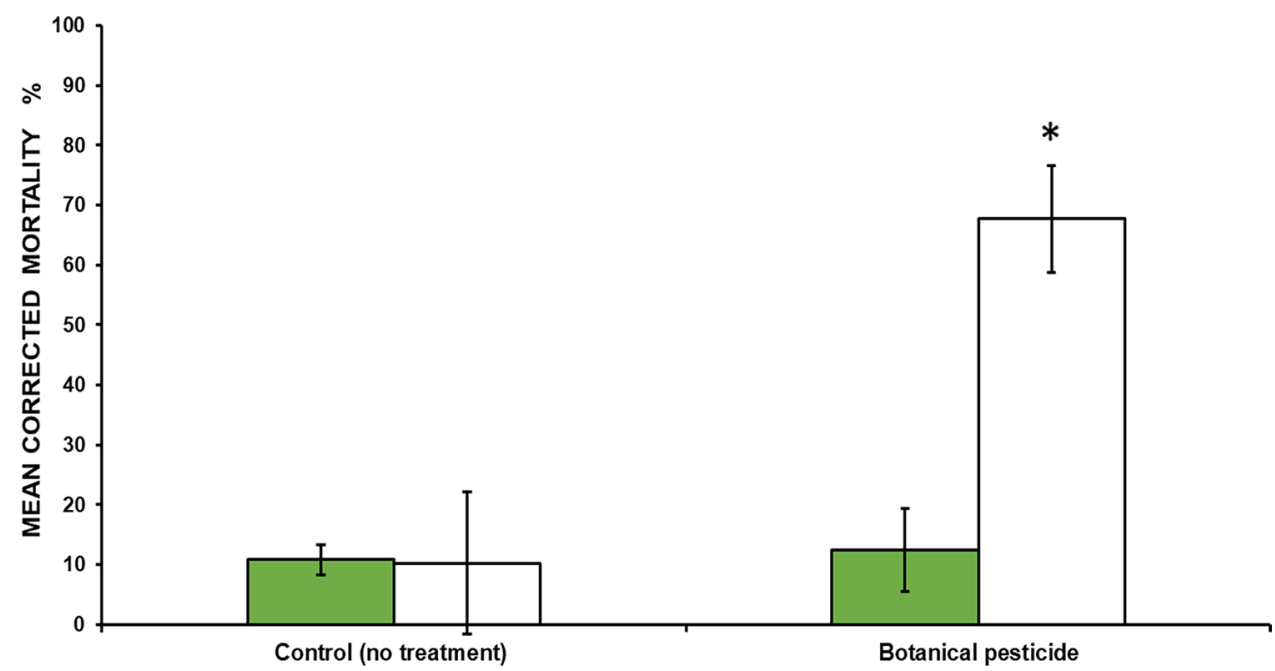

birch oils were added at a concentration of 5.3\% to the linseed oil emulsion. The highest mortality rate was found after adding garlic oil. Using the same concentration of clove, peppermint and basil oil emulsions also led to significantly higher mortality rates of desert locusts as compared to the controls ( $p<0.05, Z$-test). In contrast, the use of $5.3 \%$ ginger or eucalyptus oils did not significantly increase the toxicity of the linseed oil emulsion.

\section{Combination of essential oils}

Each of the garlic, orange peel, caraway and birch oils mixed with the linseed oil emulsion caused high mortality in the screening experiment. At lower concentrations, caraway (2.6\%), orange peel (1.3\%) and wintergreen (1.3\%) oils resulted in a rather low mortality of desert locusts after spray treatment. However, the combination of these oils in the botanical pesticide treatment increased the mortality rate of desert locusts significantly compared to all other treatments and the control situation. This botanical pesticide was more effective against migratory locusts (blank bars in Fig. 3) compared to desert locusts (blue bars in Fig. 3), where $20 \pm 7.1 \%$ survived the first day after spray treatment. However, surviving individuals were rather weak and died within in the next $16 \mathrm{~h}$ (for an example see Figure S2c, d). The expected additive mortality rate caused by four oils was $56 \%$ in Sch. gregaria and $216 \%$ in L. migratoria. The result of the Chi-squared test was 11.7 when we compared the 
expected with the observed mortality of Sch. gregaria. The critical value of this test defined for three degrees of freedom and an error probability of 0.05 is 7.8. Since the result of the Chi-squared test is higher than this critical value, a synergistic toxic effect caused by the combination of these oils was evident in Sch. gregaria. The essential oils evaporated and left no trace of scent behind when we counted the number of dead individuals $24 \mathrm{~h}$ after spray treatment. In contrast to the combined effect, spraying only the linseed oil emulsion without essential oils (control 2) had only a minor toxic effect on desert locusts $(14 \pm 16.7 \%$ mortality), but still killed $46 \pm 19.5 \%$ of migratory locust individuals, which were also more sensitive to individual essential oil treatments.

\section{$L C_{50}$ test and antifeedant effect}

The lethal concentration $\left(\mathrm{LC}_{50}\right)$ of the botanical pesticide formulation observed $40 \mathrm{~h}$ after spraying desert locusts was calculated from the regression line shown in Fig S1. At a concentration of $60 \%$, this botanical pesticide still killed $50 \%$ of desert locust individuals, which demonstrates that the toxicity of this botanical pesticide is high enough to control desert locusts effectively. To test for the additional oral toxicity of this botanical pesticide, we sprayed either desert locusts together with grass stalks or added grass stalks after the spray treatment. As can be seen in Figure S2b, the untreated locusts ate all the grass within 1 day. In fact, the desert locusts refused to feed on grass whether it was sprayed or not (Fig. S2c and d). This demonstrates a strong antifeedant effect of this botanical pesticide.

\section{Botanical pesticide experiment performed with two beetle species}

To collect preliminary data about the effect of this botanical pesticide on a beneficial and an alternative non-target species, we sprayed this formulation on ladybirds and on adult mealworm beetles (Fig. 4). Spraying adult mealworm beetles (i.e., the alternative non-target species) did not increase their mortality rates significantly. Even 8 days after treatment, the mean corrected mortality of mealworm beetles was only $12.4 \pm 7 \%$ (green bars in Fig. 4, $p>0.05, Z$-test, $N=16$, four replicates). However, spraying ladybird adults (i.e., the beneficial non-target species) caused a significant mean mortality rate of $67.7 \pm 8.9 \%$ as compared to the control group after 8 days (blank bars in Fig. $4, p<0.05, Z$-test, $N=30$, four replicates). Ladybird larvae were even more sensitive because $56.7 \pm 4.7 \%$ of all individuals died within 1 day after the botanical pesticide treatment ( $p<0.05, Z$-test, $N=15$, two replicates). Records on the effect of the botanical pesticide on the ladybird larvae could not be taken after the first $24 \mathrm{~h}$, due to the fact that the larvae cannibalized each other.

\section{Effect of the botanical pesticide on grass growth}

We sprayed the botanical pesticide on fresh wheat seedlings to investigate its impact on plant growth. We investigated the growth of the wheat seedlings that were exposed to natural sunlight on a balcony (Fig. 5a). Figure 5 shows the pots of the wheat grass 22 days after treatment. Almost no difference was observed in the shape and growth of grass stalks between the control (Fig. 5b) and the treated grass (Fig. 5c), with the exception of some yellow tips.

\section{Discussion}

Due to the hardening process of the linseed/bicarbonate emulsion (see Fig. 1), locust mobility was strongly restricted after $24 \mathrm{~h}$. This was obvious as individuals rarely jumped and moved slowly after disturbance. Adding sodium bicarbonate to the linseed oil clearly accelerated the hardening process of this oil. Bicarbonate salts are also known to be effective against fungal plant diseases. For example, Kuepper et al. (2001) provided a brief survey of the use of sodium bicarbonate $\left(\mathrm{NaHCO}_{3}\right)$ and potassium bicarbonate $\left(\mathrm{KHCO}_{3}\right)$ to control powdery mildew and other fungal diseases. Similarly, Horst et al. (1992) used sodium bicarbonate to control powdery mildew and black spot disease in roses in greenhouses and field experiments. However, spraying the linseed oil/bicarbonate emulsion on desert locusts was not very effective, since only $40 \%$ of treated individuals died within 1 day (Fig. 2). To enhance the harmful effect of this linseed oil emulsion, several essential oils were added in a screening experiment. The results of this experiment revealed that garlic, caraway, orange and birch oil emulsions were potential candidates for an insecticidal oil mixture that could kill a high proportion of locusts within a short time period. The desert locust mortality caused by these oils applied at concentration of $5.3 \%$ was equal or even exceeded $70 \%$. However, garlic oil was excluded from the next experiment because of its strong and unpleasant smell. Furthermore, birch oil was replaced by wintergreen oil, because wintergreen is more readily available and has the same active ingredient (methyl salicylate).

A formulation consisting of linseed oil and low concentrations of orange peel, wintergreen and caraway oils was then sprayed on desert locusts and migratory locusts to test its potential as a novel botanical pesticide. Results shown in Fig. 3 demonstrate that the combination of these essential oils had a strong effect on the mortality rates of the two gregarious locust species. Desert locusts were less sensitive as compared to migratory locusts, but individuals surviving the first $24 \mathrm{~h}$ died within the next $16 \mathrm{~h}$. Although the use of the same concentration of each essential oil had only a low or moderate effect on desert and migratory locust mortality, the 
Fig. 5 Spray treatment of wheat seedlings with the botanical pesticide emulsion. a Images of wheat seedlings before treatment. b Image of the untreated wheat grass taken 22 days later. c Image of the treated wheat grass 22 days after spray treatment (a)

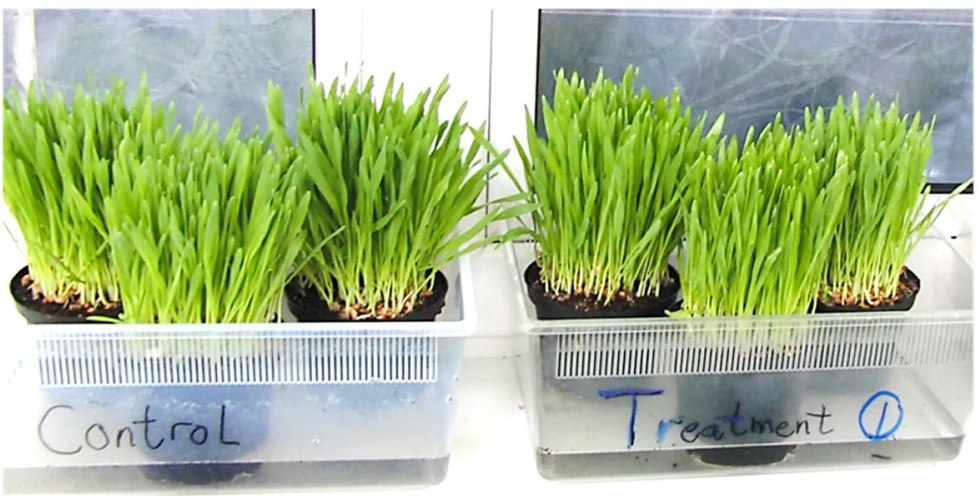

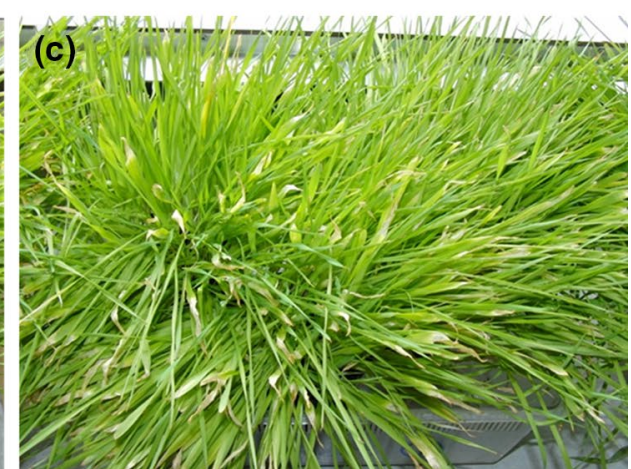

combination of the three essential oils resulted in a strong toxic effect. The results obtained with desert locusts demonstrate that these essential oils act synergistically, because the high mortality rate of desert locusts treated with the botanical pesticide cannot be explained simply by an additive toxic effect caused by each essential oil (Fig. 3).

The botanical pesticide formulation developed in this study harmed the target insects in at least two ways: First, the mobility and most likely the ventilation of the locusts were affected due to the hardening of the linseed emulsion (see Fig. 1). Second, an antifeedant effect was clearly observed, since all locusts stopped feeding immediately after the spray treatment (see Fig. S2). These results, taken together, indicate that our botanical pesticide formulation constitutes a novel, promising and effective agent that can be used to combat upsurges and locust outbreaks. This botanical pesticide formulation was then tested on two beetle species in an experiment lasting for 8 days (Fig. 4). Both beetle species are related to ecologically important beetle species (Jankielsohn 2018). Within this time span, although mealworm beetles (i.e., alternative non-target species) behaved normally, a significant, toxic effect was observed in ladybird adults (i.e., beneficial non-target species). Even more problematic a strong toxic effect was observed in the ladybird larvae that were studied for just 1 day after treatment. Mealworm beetles are less likely to come in contact with our botanical pesticide in the field, except when locusts are treated in the Mediterranean region, which is the home of this beetle species. However, given the fact that the ladybird species used in this study is related to other ladybird species in various ecosystems we cannot exclude an unwanted sideeffect on non-target insect species with important ecological functions (e.g., feeding on plant lice). However, this botanical pesticide may have only minor negative effects on the vegetation, since the growth of wheat seedlings on a balcony was not significantly affected (Fig. 5). It will be possible to use conventional spraying devices for field applications of this botanical pesticide when the emulsion is stabilized by means of an emulsifier. To avoid a toxic effect on non-target species, such as other insects (e.g., bees, beetles) and birds, it is highly recommended to spray the pesticide after sunset when the locusts rest in crowded colonies on bushes and trees.

To understand the synergistic toxic effect caused by this botanical pesticide, it is necessary to focus on its active ingredients. The main component of orange peel oil is limonene (87.9-92.5\%; Njoroge et al. 2009), but caraway oil also contains this cyclic monoterpene (1.5-51.3\%; Raal et al. 2012). A recent study demonstrated that the ventilation in the migratory locust is adversely affected by limonene in its pure form or as the major component of lovage essential oil (Halawa and Hustert 2014). Wintergreen oil mainly contains methyl salicylate (97-99.6\%; Gurung 2007), which was found to have insecticidal activity against the adzuki bean weevil $\mathrm{Cal}$ losobruchus chinensis (Park et al. 2016). Raal et al. (2012) identified carvone (44.5-95.9\%) as the main component of 
caraway oil, and Wawrzyniak and Lamparski (2006) found that aqueous extracts of caraway inhibited the feeding activity of the Colorado potato beetle Leptinotarsa decemlineata and its larvae. This suggests that caraway may be responsible for the antifeedant effect found in locusts. Additional studies, such as the one performed on the cabbage looper (Trichoplusia ni Hübner, Noctuidae, Akhtar et al. 2012), are necessary to reveal the mechanism behind the antifeedant effect of our botanical pesticide. The insecticidal effects of caraway and wintergreen oils on locusts shown in this study is novel and have not been described before.

The main component of the botanical pesticide formulation is the linseed oil, which contains omega- 3 fatty acids and has a higher linolenic acid content than other plant oils. For this reason, linseed oil is healthy and may be used as an alternative to fish oil in the human diet (Kolodziejczyk et al. 2012). Since locusts are collected and consumed as a protein source in some countries in Africa, Asia, Central and South America, Australia (Paul et al. 2016), locusts that have been stunned or killed by our botanical pesticide can be collected and used as a protein source in the human diet and the food industry. The other components of this botanical pesticide formulation are often used as preservatives and biological agents in many applications and in alternative medical treatments for human, animals and plants (Elshafie and Camele 2017).

Linseed oil becomes viscous over time when mixed with the bicarbonate solution, but it may also have an additional adverse effect on locust swarms due to the unsaturated fatty acid content. Yao et al. (2009) reported that certain unsaturated fatty acids like oleic and linoleic acid constitute necromones that are released by dead insect bodies. Necromones can be recognized by other individuals of the same or different species, where they evoke distinct behavior. For example, social insects remove the dead bodies from their nests (necrophoric behavior), whereas semi-social species avoid contact with dead or injured individuals (necrophobic behavior). Therefore, Yao et al. (2009) suggested that fatty acid necromones might be considered in many contexts, including pest management. Linseed oil contains approximately 9-11\% saturated (5-6\% palmitic acid and 4-5\% stearic acid) and $75-90 \%$ unsaturated fatty acids (50-55\% linolenic acid, 15-20\% oleic acid; Bayrak et al. 2010), which suggests that this oil may evoke necrophobic behavior in swarm mates. This might disrupt swarm formation after a certain percentage of individuals have come into contact with linseed oil. Current studies aim to reveal whether linseed oil has a possible swarm disrupting effect.

In conclusion, we were able to develop a potent novel oil mixture consisting of linseed oil and plant essential oils that displayed toxicity against locusts. This botanical pesticide contains caraway, wintergreen and orange peel oils at low concentrations. Due to a combined toxic effect, it is effective against two species of gregarious locusts (Fig. 3) while it did not harm mealworm beetles. Due to the toxic effect on the ladybird adults (Fig. 4) and its highly toxic effect on their larvae, the application of this botanical pesticide should be restricted to dense locust colonies where other non-target insects are rare. It was interesting to note that our botanical pesticide formulation did not adversely affect the growth of wheat seedlings (Fig. 5). These results suggest this formulation is an effective botanical pesticide that can be used as an alternative to chemical pesticides in the future. The components of our botanical pesticide formulation can be obtained easily at low prices, and no laboratory equipment is needed to mix the ingredients before the pesticide is applied. However, further research under field conditions is necessary to determine the effects of this novel insecticidal formulation on locust swarms and the local ecosystem.

\section{Author contributions}

ZASA and MH conceived and designed the research. ZASA conducted the experiments. ZASA analyzed the data and drafted the manuscript. MH supervised the experiments and critically read the manuscript. All authors read and approved the manuscript.

Acknowledgements Open access funding provided by Austrian Science Fund (FWF). The authors thank the Egyptian Ministry of Higher Education, Cultural Affairs and Mission Sector for providing fund for this study and Sara Crockett, a native English speaker, for proofreading. This research was conducted with support from the FWF (project P25709-B25).

\section{Compliance with ethical standards}

Conflict of interest The authors declare that they have no conflict of interest.

Ethical approval The experimental procedures were approved by the Institute of Biology (University of Graz). All experiments comply with the current Austrian and European Community laws for the ethical treatment of animals and are in line with the ASAB Guidelines for the Use of Animals in Research.

Open Access This article is distributed under the terms of the Creative Commons Attribution 4.0 International License (http://creativeco mmons.org/licenses/by/4.0/), which permits unrestricted use, distribution, and reproduction in any medium, provided you give appropriate credit to the original author(s) and the source, provide a link to the Creative Commons license, and indicate if changes were made.

\section{References}

Abdellah K, Zakaria B, Nawal B, Aminata OEH, Didi OEHM (2013) Biological activity of essential oils leaves from one Sahara plant: 
Peganum harmala L. (Zygophyllaceae) on the desert locust. Int J Curr Microbiol Appl Sci 2:389-395

Akhtar Y, Pages E, Stevens A, Bradbury R, da Camara CAG, Isman MB (2012) Effect of chemical complexity of essential oils on feeding deterrence in larvae of the cabbage looper. Physiol Entomol 37:81-91. https://doi.org/10.111 $1 / \mathrm{j} .1365-3032.2011 .00824 . x$

Alavanja MCR (2009) Pesticides use and exposure extensive worldwide. Rev Environ Health 24:303-309

Alavanja MCR, Bonner MR (2012) Occupational pesticide exposures and cancer risk: a review. J Toxicol Environ Health B 15:238-263

Aly MZY, Osman KSM, Mohanny KM, Abd Elatti ZAS (2012) Indoor and outdoor controlling evaluation on the subterranean termite, Psammotermes hybostoma (Isoptera: Rhinotermitidae) using some unordinary natural oils and others. Egypt Acad J Biol Sci A Entomol 5:175-189

Arshad Z, Hanif MA, Qadri RWK, Khan MM (2014) Role of essential oils in plant diseases protection: a review. IJCBS 6:11-17

Arthurs S (2008) Grasshoppers and Locusts as Agricultural Pests. In: Capinera JL (ed) Encyclopedia of Entomology. Springer, Dordrecht, pp 1690-1694

Bayrak A, Kiralan M, Ipek A, Arslan N, Cosge B, Khawar KM (2010) Fatty acid compositions of linseed (Linum usitatissimum L.) genotypes of different origin cultivated in Turkey. Biotechnol Biotechnol Equip 24:1836-1842. https://doi.org/10.2478/V1013 3-010-0034-2

Bliss CI (1939) The toxicity of poisons applied jointly. Ann Appl Biol 26:585-615

Brader L, Djibo H, Faye FG, Ghaout S, Lazar M (2006) Towards a more effective response to desert locusts and their impacts on food security, livelihoods and poverty. In: Proceedings of independent multilateral evaluation of the 2003-2005 desert Locust Campaign, FAO, Rome

Carvalho FB (2017) Pesticides, environment, and food safety. Food Energy Secur 6:48-60. https://doi.org/10.1002/fes3.108

Cedergreen N (2014) Quantifying synergy: a systematic review of mixture toxicity studies within environmental toxicology. PLoS ONE 9:e96580. https://doi.org/10.1371/journal.pone.0096580

EL Rasheed S, EL Rasheed AS (2017) Vegetable diseases control by using essential oils to access organic production in Sudan. Agric Res Technol J 6:555694. https://doi.org/10.19080/ARTOA J.2017.06.555694

Elshafie HS, Camele I (2017) An overview of the biological effects of some Mediterranean essential oils on human health. Biomed Res Int. https://doi.org/10.1155/2017/9268468

FAO (2009) FAO Desert Locust Control Committee. Thirty-ninth session. Food and Agriculture Organization of the United Nations, Rome

Gurung K (2007) Analysis of wintergreen oil extracted from leaves of wintergreen in distillation units of Dolakha. Ecology Agriculture and Rural Development Society (ECARDS), Charikot, Dolakha. https://de.scribd.com/doc/8726619/Analysis-of-Wintergreen-Oil. Accessed 5 June 2018

Halawa SM, Hustert R (2014) Neural activity of a locust ganglion is impaired by limonene and Lovage (Levisticum officinale) extracts. J Entomol 11:1-13. https://doi.org/10.3923/je.2014.1.13

Horst RK, Kawamoto SO, Porter LL (1992) Effect of sodium bicarbonate and oils on the control of powdery mildew and black spot of roses. Plant Dis 76:247-251. https://doi.org/10.1094/PD-76-0247

Isman MB (2004) Plant essential oils as green pesticides for pest and disease management. In: Agricultural applications in green chemistry, ACS symposium series vol 887, chapter 4. pp 41-51. https ://doi.org/10.1021/bk-2004-0887.ch004

Jankielsohn A (2018) The importance of insects in agricultural ecosystems. Adv Entomol 6:62-73
Köhler HR, Triebskorn R (2013) Wildlife ecotoxicology of pesticides: can we track effects to the population level and beyond? Science 341:759-765

Kolodziejczyk P, Ozimek L, Kozłowska J (2012) The application of flax and hemp seeds in food, animal feed and cosmetics production, handbook of natural fibres-processing and applications. Woodhead Publ Ser Text 2:329-366. https://doi. org/10.1533/9780857095510.2.329

Kuepper G, Thomas R, Earles R (2001) Use of baking soda as a fungicide. National Center for Appropriate Technology. https://attra .ncat.org/attra-pub/viewhtml.php?id=126

Lahsen EG, Driss E, Meryem B, Nabil E, Hassan EH, Mohammed AM, Petit D (2015) Chemical composition of essential oils from Rosmarinus officinalis L. and acridicide activity on Dociostaurus maroccanus Thunberg, 1815 in Morocco. IJSER 6:16-172

Latchininsky AV (2013) Locusts and remote sensing: a review. J App Rem Sens 7:075099. https://doi.org/10.1117/1.JRS.7.075099

Lecoq M (2010) Integrated pest management for locusts and grasshoppers: are alternatives to chemical pesticides credible? J Orthoptera Res 19:131-132

Millist N, Abdalla A (2011) Benefit-cost analysis of Australian plague locust control operations for 2010-11. ABARES report prepared for the Australian Plague Locust Commission 2011. 17 pp http:// www.agriculture.gov.au/SiteCollectionDocuments/animal-plant/ aplc/research-papers/locust-control-11.pdf

Nicolopoulou-Stamati P, Maipas S, Kotampasi C, Stamatis P, Hens L (2016) Chemical pesticides and human health: the urgent need for a new concept in agriculture. Front Public Health 4:148. https:// doi.org/10.3389/fpubh.2016.00148

Njoroge SM, Phi NTL, Sawamura M (2009) Chemical composition of peel essential oils of sweet oranges (Citrus sinensis) from Uganda and Rwanda. J Essent Oil Bear Pl 12:26-33. https://doi. org/10.1080/0972060X.2009.10643687

Park CG, Shin E, Kim J (2016) Insecticidal activities of essential oils, Gaultheria fragrantissima and Illicium verum, their components and analogs against Callosobruchus chinensis adults. J Asia Pac Entomol 19:269-273. https://doi.org/10.1016/j.aspen.2016.03.001

Paul A, Frederich M, Uyttenbroeck R, Hatt S, Malik P, Lebecque S, Malik H, Miazek K, Goffin D, Willems L, Deleu M, Fauconnier M-L, Richel A, De Pauw E, Blecker C, Monty A, Francis F, Haubruge E, Danthine S (2016) Grasshoppers as a food source? A review. Biotechnol Agron Soc Environ 20:337-352

Püntener W (1981) Manual for field trials in plant protection, 2nd edn. Ciba-Geigy Limited, Basle, Switzerland, p 205

Raal A, Arak E, Orav A (2012) The content and composition of the essential oil Found in Carum carvi L. commercial fruits obtained from different countries. J Essent Oil Res 24:53-59. https://doi. org/10.1080/10412905.2012.646016

Sharaby A, Montasser SA, Mahmoud YA, Ibrahim SA (2012) Natural plant essential oils for controlling the grasshopper (Heteracris littoralis) and their pathological effects on the alimentary canal. Ecol Balk 4:39-52

Steedman A (1988) Locust handbook. Overseas Development Natural Resources Institute, London, UK

Sturchio E, Donnarumma L, Annesi T, Milano F, Casorri L, Masciarelli E, Zanellato M, Meconi C, Boccia P (2014) Essential oils: an alternative approach to management of powdery mildew diseases. Phytopathol Mediterr 53:385-395. https://doi.org/10.14601/Phyto pathol_Mediterr-13607

Tak JH (2015) A study of insecticidal synergy of plant essential oil constitunts against Trichoplusia ni. Dissertation in plant science, The University of British Columbia

Tak JH, Jovel E, Isman MB (2016) Comparataive and synergistic activity of Rosmarinus officinalis L. essential oil constituents against the larvae and an ovarian cell line of the cabbage looper Trichoplusia ni (Lepidoptera: Noctuidae). Pest Manag Sci 72(3):474-480 
Tak JH, Jovel E, Isman MB (2017) Synergistic interactions among the major constituents of lemongrass essential oil against larvae and an ovarian cell line of the cabbage looper, Trichoplusia ni. J Pest Sci 90(2):735-744. https://doi.org/10.1007/s10340-016-0827-7

Tounou A-K, Kooyman C, Douro-Kpindou O-K, Poehling H-M (2008) Interaction between Paranosema locustae and Metarhizium anisopliae var. acridum, two pathogens of the desert locust, Schistocerca gregaria under laboratory conditions. J Inv Pathol 97:203-210. https://doi.org/10.1016/j.jip.2007.10.002

Tripathi AK, Upadhyay S, Bhuiyan M, Bhattacharya PR (2009) A review on prospects of essential oils as biopesticide in insect-pest management. J Pharmacogn Phytother 1:000

Uvarov B (1966) Grasshoppers and locusts. A handbook of general acridology, vol 1. Cambridge University Press, Cambridge

Wawrzyniak M, Lamparski R (2006) Effect of Umbelliferae (Apiaceae) plant water extracts on Colorado potato beetle (Leptinotarsa decemlineata Say) feeding and development. EJPAU 9. http:// www.ejpau.media.pl/volume9/issue4/art-23.html. Accessed 12 June 2018

World Health Organization (1990) Public health impact of pesticides used in agriculture. World Health Organization, Geneva
World Health Organization (2012) The WHO recommended classification of pesticides by hazard and guidelines to classification. World Health Organization, Geneva

World Health Organization (2016) Global malaria programme. Test procedures for insecticide resistance monitoring in malaria vector mosquitoes, $2 \mathrm{~d}$ edn. World Health Organization. http://www.who. int/iris/handle/10665/250677. Accessed 26 June 2018

Wright DE (1986) Economic assessment of actual and potential damage to crops caused by the 1984 locust plague in south-eastern Australia. J Environ Manag 23:293-308

Yao M, Rosenfeld J, Attridge S, Sidhu S, Aksenov V, Rollo CD (2009) The ancient chemistry of avoiding risks of predation and disease. Evol Biol 36:267-281. https://doi.org/10.1007/s1169 2-009-9069-4

Zhang L, Hunter DM (2017) Management of locusts and grasshoppers in China. J Orthoptera Res 26:155-159. https://doi.org/10.3897/ jor.26.20119

Publisher's Note Springer Nature remains neutral with regard to jurisdictional claims in published maps and institutional affiliations. 